DOI: 10.20472/IAC.2018.043.001

TAKAYASU ITO

Meiji University, Scool of Commerce, Japan

\title{
DIFFERENT PROPERTY SECTORS OF JAPANESE REIT MARKET: COMPARATIVE ANALYSIS OF DETERMINANTS UNDER NON-TRADITIONAL MONETARY POLICY REGIMES
}

\begin{abstract}
:
Stock price has a positive impact on the REIT (Real Estate Investment Trust) Property Sector Index Series (Office, Residential, and Retail \& Logistics) in all three sample periods. Interest rate has no significant impact on any of the sectors in the REIT Property Sector Index Series under the comprehensive easing policy regime. On the other hand, interest rate has a negative impact on each of the sectors in the REIT Property Sector Index Series under the quantitative and qualitative easing and the negative interest rate policy regimes. The negative impact of interest rate on the REIT market is larger under the quantitative and qualitative policy regime than it is under the negative interest rate policy regime. As regards the sensitivity of the three REIT property sectors to stock price and interest rate, no significant differences are found in any of the samples; the three different sectors are almost equally influenced by stock price and long-term interest rate.
\end{abstract}

\section{Keywords:}

REIT Property Sector, Stock Price, Swap Rate, Non-Traditional Monetary Policy

JEL Classification: E44, E58, G19 